\title{
Stock Selection Skills of Indian Mutual Fund Managers during 2000-2012
}

\author{
Joyjit Dhar \\ Assistant Professor, Department Of Economics, Krishnagar Government College, West Bengal, India
}

\begin{abstract}
Mutual funds work on the basis of two maxims - maximization of returns and diversification of risk, the attainment of which requires healthy operational practices and efficient investment management. Now, systematic investment management involves a wide variety of activities among which selectivity plays the pivotal role in the return generation process. This study is an attempt to evaluate the investment management of Indian mutual funds in terms of selectivity skills of fund managers during May 31, 2000 to March 31, 2012.

The results pertaining to the selectivity skills of fund managers, as found in the study, has revealed that although majority of the schemes have shown positive alpha they are not statistically significant. Only some of the fund managers (around twenty five percent) possess superior selectivity skills based on both unconditional and conditional Jensen model. Conditioning on public information however improves the coefficient of determination.

JEL classification: G11; G23

Keywords: CAPM, Conditional performance evaluation, Investment management, Mutual funds, Selectivity.
\end{abstract}

\section{Introduction}

Mutual funds work on the basis of two maxims - maximization of returns and diversification of risk, the attainment of which requires healthy operational practices and efficient investment management. Systematic investment management involves a variety of activities such as stock selection(selectivity), asset allocation, management style and market timing. However, the performance of a portfolio manager can be measured in terms of stock selection ability or selectivity.

Stock selection is the nucleus in the investment management process. Investment performance of stock selection owes to the successful forecasting of the price movements of individual securities and/or an ability to predict the general behavior of security prices in the future i.e. the impact of market factor (Jensen, 1968). Thus, if the manager is unable to forecast general market movements then it is possible to increase returns on the portfolio by choosing individual securities which are undervalued. On the contrary, if the manager has an ability to forecast market movements then the estimated performance measure will be biased upward as the estimated risk parameter will be biased downward.

In the literature there are several methods to examine the selectivity skills of the fund managers. However, this study evaluates investment managers' selectivity skills in terms of the theoretical model developed by Jensen (1968).

The study has also adopted conditional performance evaluation measures in order to evaluate performance of Indian mutual funds schemes. In doing so, traditional performance measures are modified in this study. The remainder of the paper is organized as follows. Section 2 deals with the literature on selectivity. Section 3 describes our methodology. Section 4 presents empirical results and Section 5 concludes.

\section{Review of Literature}

Jensen [1] developed an absolute measure of performance to evaluate the investment manager's predictive ability- that is his ability to earn higher returns through successful prediction of security prices. In this model, excess fund returns are regressed upon the excess market returns and the intercept of this regression, known as alpha, shows the differential return earned by the scheme because of investment managers' predictive abilities. By evaluating the performance of 115 open-end mutual funds over the period 1945-1964 Jensen found that on average investment managers were not able to predict security prices efficiently to outperform the market. The study found little evidence that the individual fund was able to do significantly better than that expected from mere random chance.

Fama[2] suggested alternative performance evaluation methods where the overall performance of a managed portfolio could be broken down into several components. He argued that while observed return of a fund could be due to the ability of fund managers to pick up best securities at a given level of risk (selectivity), it could also arise due to prediction of general market price movements i.e. their timing ability. Selectivity can be further decomposed into net selectivity and diversification. 
Grinblatt and Titman[3] examined whether there were fund managers who had superior stock selection abilities to generate abnormal returns-both with and without transaction costs, fees and expenses. Applying Jensen's measure they concluded that superior performance might exist among growth funds and also among funds with the smallest net asset values. However, as these funds also had the highest expenses actual returns net of expenses did not show superior performance.

Ferson and Schadt[4] advocated conditional performance evaluation in which relevant expectations are conditioned on public information variables. Using monthly data for 67 mutual funds during 1968-1990 they found that risk exposures of the sample schemes changed in response to public information on the economy. Moreover, the use of conditioning information in performance measurement is both statistically and economically significant.

Sawicki and Ong[5] applied both unconditional and conditional models for the performance evaluation of Australian funds. Using 97 funds the study found that use of conditioning information improved the performance of the funds and the distribution of the alphas shifted towards zero.

In the Indian context, one of the early works in the area was made by Jayadev [6]. This study used traditional unconditional form to a sample of 44 mutual fund schemes over a period of 1987 to 1994 and found that t-value of alpha is significant only for one scheme.

Irissapane et al [7] evaluated performance of Indian mutual funds for a sample of 34 mutual fund schemes during 1988 to 1998 . The study was based on unconditional CAPM model and revealed that though most of the schemes showed positive alpha coefficients they are not statistically significant.

Gupta and Gupta [8] found no conclusive evidence in support of the superior stock selection performance of the Indian mutual fund managers.

Anand and Murugaiah [9] also found lack of superior stock selectivity among the fund managers of 113 mutual fund schemes during April 1999 to March 2003.

However, in an illuminating paper Chander [10] made an attempt to evaluate the stock selection abilities of Indian fund managers for a sample of 80 schemes during 1998-2002. This study revealed significant stock selection abilities of Indian fund managers across the fund characteristics as well as the persistence of such selectivity skills of fund managers. The study also reported consistency of performance across the measurement criteria.

Sehgal and Jhanwar[11] also showed improved evidence of selectivity using higher frequency data such as daily returns against monthly returns of 59 mutual fund schemes during 2000-2004.

\section{Methodology}

The objective of the study is to assess the investment management of mutual funds in evaluating their performance during the period May 2000 to March 2012. This period is chosen since during this period Indian capital market has witnessed major upheavals as a result of (i) changes in economic policies by the government at the centre in order to expedite the reforms programme as well as (ii) occurrence of important events on the domestic and international front. The empirical part of the study proceeds as follows:

(1) At the outset, this study tries to evaluate the selectivity skills of fund managers in India during May 2000 to March 2012 using unconditional models. Besides, it examines relation between selectivity and fund objective.

(2) Secondly, this study tries to evaluate the selectivity of fund managers in India during May 2000 to March 2012 using the conditional models. The study also examines relation between selectivity and fund objective. The present study uses a sample of eighty mutual fund schemes both from the public as well as from private sector for performance evaluation. Out of eighty schemes fifty six belong to private sector while twenty four belong to the public sector, so far as ownership pattern of the schemes are considered. According to the investment objective, the sample comprises of sixty six growth schemes and fourteen equity linked savings schemes (ELSS). The details of the sample schemes are given in Appendix-I.

\subsection{Data}

This study is based on secondary data. The secondary data have been collected for a sample of eighty mutual funds schemes for the period May 31, 2000 to March 31, 2012. These eighty schemes are from both public as well as private sector. Out of these eighty schemes sixty six are growth schemes and fourteen are equity linked savings schemes (ELSS). Since balanced schemes of the sample are basically equity oriented they are also treated as equity schemes. As our sample contains only surviving schemes the result may have a survivorship bias which may lead to the biased performance.

The data used in the study mainly comprise of monthly net asset values (NAV) for the eighty mutual funds schemes during May 31, 2000 to March 31, 2012. These NAV data are collected from www.mutualfundsindia.com . In order to explore selectivity skills this study has used Sensex as the market proxy. These data are collected from the Prowess database of CMIE. Generally, treasury bills of different 
durations have been used as a surrogate for risk-free asset in studies of developed as well as emerging economies. In this study the monthly yield on 91day treasury bills of GOI is used as a market proxy for risk-free return. These data are collected from RBI website.

For the conditional model we need further information on market dividend yield (DP) and growth rate of index of industrial production (IIPg). The annualized dividend yield on the Sensex is given on a monthly basis in www.bseindia.com. As these monthly dividend figures are given in annual form the study converted them to the monthly figures. So far as index of industrial production (IIP) is concerned the monthly IIP data are collected from RBI website. From this monthly data monthly IIPg is determined.

\subsection{Estimation} equation:

At the outset, the returns for each of the sample schemes have been computed by using the following

$$
\mathrm{R}_{\mathrm{t}}=\left(\mathrm{NAV}_{\mathrm{t}}-\mathrm{NAV}_{\mathrm{t}-1}+\mathrm{D}_{\mathrm{t}}\right) / \mathrm{NAV}_{\mathrm{t}-1}
$$

Similarly, the returns for the market index (Sensex) have been computed. The return on the risk-free asset, i.e., the yields on 91-day T-bills is given on annual basis in the RBI website which is converted to the monthly basis. The total risk of investing in a portfolio is measured by the standard deviation of the monthly returns of the portfolio and the systematic risk (Beta) of the portfolio is measured by the following CAPM version of the market model:

$$
\begin{aligned}
& \mathrm{R}_{\mathrm{pt}}=\alpha+\beta \mathrm{R}_{\mathrm{mt}}+\varepsilon_{\mathrm{pt}} \ldots \ldots \ldots \text { (2) } \\
& \text { where, } \\
& \mathrm{R}_{\mathrm{pt}}=\text { return on fund ' } \mathrm{p} \text { ' for period } \mathrm{t} \\
& \mathrm{R}_{\mathrm{mt}}=\text { return on the market index for period } \mathrm{t} \\
& \varepsilon_{\mathrm{pt}}=\text { random error term } \\
& \beta=\text { measure of systematic risk } \\
& \alpha=\text { a constant term }
\end{aligned}
$$

Higher value of $\beta$ indicates high sensitivity of fund returns against market returns, the lower value indicates a low sensitivity.

\subsubsection{Selectivity}

The selectivity skill of the fund managers are assessed in terms of Jensen [1] criterion. Jensen's model helps to evaluate the selectivity skills of fund managers, i.e. their ability to identify under-valued or over-valued securities. The superior returns earned out of the ability of stock selection can be known from Jensen's alpha. Jensen's measure may be given as follows:

$$
\begin{aligned}
\mathrm{R}_{\mathrm{pt}}-\mathrm{R}_{\mathrm{ft}} & =\alpha+\beta\left(\mathrm{R}_{\mathrm{mt}}-\mathrm{R}_{\mathrm{ft}}\right)+\varepsilon_{\mathrm{pt}} \ldots \ldots \ldots \ldots . . .(3) \\
\text { where, } & \\
\mathrm{R}_{\mathrm{pt}} & =\text { return of the fund ' } \mathrm{p} \text { ' for period' } \mathrm{t} \text { ' } \\
\mathrm{R}_{\mathrm{ft}} & =\text { risk-free return for period' } \mathrm{t} \text { ' } \\
\mathrm{R}_{\mathrm{mt}} & =\text { return on the benchmark (market) portfolio for } \\
& \text { period' } \mathrm{t} \text { ' } \\
\varepsilon_{\mathrm{pt}} & =\text { random error term }
\end{aligned}
$$

$\alpha, \beta$ are the parameters of the model and are estimated by OLS technique. A positive and significant value of $\alpha$ will indicate superior selectivity skills of the fund managers. In this study the selectivity skills of fund managers are measured by the significance of the intercept term of the unconditional and conditional Jensen models.

\subsubsection{Rationale of Conditional Models}

The traditional asset pricing models (unconditional models) cannot capture the dynamic behavior of expected returns. If expected returns and risks vary over time unconditional models are not likely to be reliable. Moreover, it is argued that, unconditional models can attribute abnormal performance for an investment strategy that is based only on public information. Now, it is possible to control the effect of such common public information and reduce this source of bias by using the instruments for time-varying expectations. Ferson and Schadt[4] advocated conditional performance evaluation in order to avoid this source of bias. For stock selection ability the objective is to distinguish selectivity that merely reflects publicly available information from selectivity based on private information. The reason behind such objective is that the managers who mechanically use only public information should get no credit for 'superior' ability. This is because any knowledgeable investor will also have similar kind of information and will react accordingly and attempts by many such knowledgeable investors will cancel out the informational advantage. The manager's true skill lies in generating the private information and as such his true stock selection ability lies in responding to this private information only. Conditional models presume that portfolio managers can change both their alphas and betas over time depending on the publicly available information about the economy. In most of the works two most 
important public information variables incorporated in the market timing models are dividend yield of the market index and short term Treasury bill yield. The present study has considered monthly growth rate of index of industrial production (IIP) as another macroeconomic variable for conditioning the alphas and betas of funds. In general, the incentive to invest in capital market by the institutional investors is largely influenced by the performance of the real economy. Here, we have considered IIP growth rate as a proxy for the performance of the real economy.

The conditional Jensen model is given as follows:

$\mathbf{R}_{\mathrm{pt}}-\mathbf{R}_{\mathrm{ft}}=\alpha+\boldsymbol{\beta}_{0}\left(\mathbf{R}_{\mathrm{mt}}-\mathbf{R}_{\mathrm{ft}}\right)+\boldsymbol{\beta}_{1}\left(\mathbf{R}_{\mathrm{mt}}-\mathbf{R}_{\mathrm{ft}}\right) \mathbf{D P _ { \mathrm { t } - 1 }}+\boldsymbol{\beta}_{2}\left(\mathbf{R}_{\mathrm{mt}}-\mathbf{R}_{\mathrm{ft}}\right) \mathbf{T B}_{\mathrm{t}-1}+\boldsymbol{\beta}_{3}\left(\mathbf{R}_{\mathrm{mt}}-\mathbf{R}_{\mathrm{ft}}\right) \operatorname{IIPg_{\mathrm {t}-1}}++\varepsilon_{\mathrm{pt}}$

where,

$\mathrm{DP}_{\mathrm{t}-1}=$ lagged dividend yield of BSE Sensex

$\mathrm{TB}_{\mathrm{t}-1}=$ lagged 91day Treasury bill yield

$\mathrm{IIPg}_{\mathrm{t}-1}=$ lagged monthly growth rate of index of industrial production

$\alpha, \beta s$ and $\gamma$ are the parameters of the model and can be estimated by the standard OLS technique while all other symbols have their usual meanings.

\section{Evidence of Selectivity}

\section{Empirical Results} given in Table I.

The results of selectivity skills of fund managers in terms of unconditional Jensen[1] formulation is

Table I is to be inserted here.

According to the unconditional model majority of the schemes (56 schemes) have positive alphas (given in Appendix II).But, it is difficult to infer whether this is due to random chance or superior selectivity skills of the fund managers. For this statistical significance of the estimated performance measures are required. A closer look at table I suggests that of these fifty six schemes portfolio managers of twenty schemes have superior selectivity skills in terms of unconditional Jensen model. This is because for these twenty schemes $\alpha$ coefficients are positive and their corresponding t-ratios are significant at five percent level. Top three schemes with significant positive abnormal performances as per unconditional CAPM are HDFC Top 200, FT India Balanced Fund and Franklin India Prima Plus. However, there is only one scheme for which the t-value of the alpha coefficient is significant but coefficient itself is negative thereby indicating inferior stock selection abilities of the managers. Thus, on the whole, the results of selectivity based on unconditional model reveal that some of the Indian fund managers had superior selectivity skills during the period under consideration.

\section{Table II is to be inserted here.}

Table II shows that mean and median values of the equity and ELSS schemes are greater than their balanced counterparts. Hence, it can be inferred that on the average fund managers of equity schemes (pure equity\& ELSS schemes) have superior selectivity skills than the fund managers of balanced schemes during the period under consideration. Further, standard deviation values show that balanced schemes are more volatile than equity schemes in achieving superior selectivity skills which is no doubt a trivial outcome.

Table III is to be inserted here.

The use of conditional version of the Jensen[1] model gives us almost same results for selectivity. Of the eighty schemes under consideration fifty five (55schemes) schemes are found to show positive alphas (given in Appendix II). However, from Table III it is evident that among these fifty five schemes there are eighteen schemes for which alphas coefficients are positive and their corresponding t-ratios are significant at five percent level thereby indicating that managers have the superior selectivity skills. Top three schemes with significant positive abnormal performances as per conditional CAPM are Franklin India Prima Plus, HDFC Top 200 and FT India Balanced Fund. The results are very much circular in nature taking into account the unconditional model. Nevertheless, what is intriguing here is that eighteen schemes under conditional model are not same as in the unconditional model. But, conditioning on public information improves the coefficient of determination. This implies that model specification in the conditional framework is better than its unconditional counterpart. 
Table IV is to be inserted here.

Basic descriptive statistics of selectivity performance given in Table IV unveils that mean and median value of the pure equity schemes are greater than ELSS and balanced schemes. This actually indicates that fund managers of pure equity schemes are most efficient to select stocks with greater return potentiality followed by ELSS and balanced schemes. However, standard deviation values based on the conditional CAPM model show that pure equity schemes are most vulnerable to posit positive selectivity skills followed by ELSS and balanced schemes. This result is quite consistent with the very nature of the objectives of the schemes. Thus, once we control for the public information variables the biases resulting from the unconditional models are removed.

\section{Conclusion}

The present study has examined the selectivity skills of fund managers for a sample of eighty mutual fund schemes during May2000 to March 2012 using monthly data frequency. For this the study has applied both unconditional and conditional models. The results pertaining to the selectivity skills of fund managers, as found in the study, has revealed that some of the fund managers(around twenty five percent) possess superior selectivity skills based on both unconditional and conditional Jensen[1] model. Although majority of the schemes have shown positive alpha but they are not statistically significant. This result is very much in line with the study of Irissapane [7] and Jayadev[6]. So there is very little difference between unconditional and conditional models in the Indian context so far as indicator of abnormal performance is concerned.

However, if we go by investment objectives then the results obtained from conditional model is consistent with the very nature of the objectives of the schemes which are in striking contrast with the unconditional model. Accordingly, it can be argued that conditioning on public information eliminates the biases arise from unconditional model. This actually confirms earlier findings of Ferson and Schadt[4], Sawicki and Ong[5] etc. Further, Conditioning on public information improves the coefficient of determination.

Thus, the results obtained in the study do not support the hypothesis that Indian mutual fund managers display superior selectivity skills even if we control for the public information variables. But there is evidence that some of the fund managers are able to show superior stock picking ability.

Table I- Results of Unconditional Jensen Model (Only results of schemes having selectivity are shown here)

\begin{tabular}{|c|c|c|c|c|}
\hline Sl. No. & Name of the Scheme & $\boldsymbol{\alpha}$ & $\mathbf{t} \boldsymbol{\alpha}$ & $\mathbf{R}^{\mathbf{2}}$ \\
\hline 1 & Birla Sun Life MNC Fund & 0.008481 & $2.183060^{*}$ & 0.734556 \\
\hline 2 & Canara Robeco Balance & 0.006735 & $2.365181^{*}$ & 0.822546 \\
\hline 3 & $\begin{array}{c}\text { DSP BlackRock Balanced } \\
\text { Fund - Growth }\end{array}$ & 0.006715 & $2.853033^{*}$ & 0.865945 \\
\hline 4 & $\begin{array}{c}\text { DSP BlackRock } \\
\text { Opportunities Fund }\end{array}$ & 0.007958 & $2.357489^{*}$ & 0.867590 \\
\hline 5 & Franklin India Bluechip & 0.008432 & $3.082347^{*}$ & 0.903325 \\
\hline 6 & Franklin India Prima Plus & 0.009317 & $3.339883^{*}$ & 0.888847 \\
\hline 7 & Franklin India Taxshield & 0.006837 & $2.239933^{*}$ & 0.880605 \\
\hline 8 & FT India Balanced Fund & 0.009039 & $3.402675^{*}$ & 0.847730 \\
\hline 9 & HDFC Balanced Fund & 0.006498 & $2.701403^{*}$ & 0.861072 \\
\hline 10 & HDFC Growth Fund & 0.008162 & 2.470391 & 0.864531 \\
\hline 11 & HDFC Prudence Fund & 0.013721 & $2.837630^{*}$ & 0.553813 \\
\hline 12 & HDFC Taxsaver & 0.011368 & $3.296176^{*}$ & 0.853397 \\
\hline 13 & HDFC Top 200 & 0.011183 & $3.626229^{*}$ & 0.887880 \\
\hline 14 & ICICI Prudential Balanced & 0.005454 & $2.250178^{*}$ & 0.848819 \\
\hline 15 & ICICI Prudential FMCG & 0.012149 & $2.248581^{*}$ & 0.473173 \\
\hline 16 & ICICI Prudential Taxplan & 0.010383 & $2.128210^{*}$ & 0.770347 \\
\hline 17 & Reliance Growth & 0.013460 & $2.892479^{*}$ & 0.793365 \\
\hline 18 & Reliance Vision & 0.012337 & $2.845518^{*}$ & 0.791552 \\
\hline 19 & Tata Balanced Fund & 0.006310 & $2.363084^{*}$ & 0.836937 \\
\hline 20 & Templeton India Growth & 0.007950 & $2.500579^{*}$ & 0.877732 \\
& & & & \\
\hline
\end{tabular}

* Significant at 5\% level 
Table II- Basic Descriptive Statistics of Selectivity (based on Unconditional Jensen Model)

\begin{tabular}{|l|c|c|c|}
\hline & Equity & Balanced & ELSS \\
\hline Mean & 0.009943 & 0.007782 & 0.009529 \\
\hline Median & 0.008899 & 0.006715 & 0.010383 \\
\hline S.D. & 0.002119 & 0.002838 & 0.002383 \\
\hline
\end{tabular}

Table III- Results of Conditional Jensen Model

(Only results of schemes having selectivity or are shown here)

\begin{tabular}{|c|c|c|c|c|}
\hline Sl. No. & Name of the Scheme & $\boldsymbol{\alpha}$ & $\mathbf{t} \boldsymbol{\alpha}$ & $\mathbf{R}^{\mathbf{2}}$ \\
\hline 1 & Canara Robeco Balance & 0.007424 & $2.530926^{*}$ & 0.827927 \\
\hline 2 & DSP BlackRock Balanced Fund & 0.007144 & $2.923157^{*}$ & 0.867985 \\
\hline 3 & DSP BlackRock Opportunities Fund & 0.007755 & $2.211510^{*}$ & 0.869431 \\
\hline 4 & Escorts Tax Plan & 0.007785 & $2.736576^{*}$ & 0.904447 \\
\hline 5 & Franklin India Prima Plus & 0.010047 & $3.469884^{*}$ & 0.890560 \\
\hline 6 & Franklin India Taxshield & 0.007089 & $2.222101^{*}$ & 0.880825 \\
\hline 7 & FT India Balanced Fund & 0.008468 & $3.114750^{*}$ & 0.851947 \\
\hline 8 & HDFC Prudence Fund & 0.009587 & $2.046677^{*}$ & 0.621501 \\
\hline 9 & HDFC Taxsaver & 0.010436 & $2.945028^{*}$ & 0.858678 \\
\hline 10 & HDFC Top 200 & 0.009937 & $3.159065^{*}$ & 0.893503 \\
\hline 11 & ICICI Prudential Balanced & 0.006101 & $2.464377^{*}$ & 0.856018 \\
\hline 12 & ICICI Prudential FMCG & 0.011571 & $2.092197^{*}$ & 0.496037 \\
\hline 13 & ICICI Prudential Top 100 Fund & 0.005728 & $2.037023^{*}$ & 0.897017 \\
\hline 14 & Reliance Growth & 0.012806 & $2.670038^{*}$ & 0.799626 \\
\hline 15 & Reliance Vision & 0.012440 & $2.748897^{*}$ & 0.792694 \\
\hline 16 & Sundaram Balanced Fund & 0.004935 & $2.106759^{*}$ & 0.890639 \\
\hline 17 & Tata Balanced Fund & 0.006615 & $2.361155^{*}$ & 0.837783 \\
\hline 18 & Templeton India Growth Fund & 0.007905 & $2.392495^{*}$ & 0.879349 \\
\hline
\end{tabular}

* Significant at 5\% level

Table IV- Basic Descriptive Statistics of Selectivity (based on Conditional Jensen Model)

\begin{tabular}{|l|c|c|c|}
\hline & Equity & Balanced & ELSS \\
\hline Mean & 0.009492 & 0.007182 & 0.008437 \\
\hline Median & 0.009937 & 0.007144 & 0.007785 \\
\hline S.D. & 0.002482 & 0.001530 & 0.001766 \\
\hline
\end{tabular}

Appendix -I

Sample Mutual Fund Schemes

\begin{tabular}{|c|c|c|}
\hline Sl. No. & Name of the Scheme & Aim \\
\hline 1. & Baroda Pioneer ELSS 96 & TP \\
\hline 2. & Birla Sun Life 95 & G \\
\hline 3. & Birla Sun Life Advantage Fund & G \\
\hline 4. & Birla Sun Life buy India Fund & G \\
\hline 5. & Birla Sun Life Equity Fund & G \\
\hline 6. & Birla Sun Life India Opportunities Fund & G \\
\hline 7. & Birla Sun Life MNC Fund & G \\
\hline 8. & Birla Sun Life New Millennium & B \\
\hline 9. & Canara Robeco Balance & B \\
\hline 10. & DSP BlackRock Balanced Fund & G \\
\hline 11. & DSP BlackRock Opportunities Fund & G \\
\hline 12. & DSP BlackRock Technology.com Fund & TP \\
\hline 13. & Escorts Tax Plan & G \\
\hline 14. & Franklin India Bluechip & G \\
\hline 15. & Franklin India Opportunity Fund & G \\
\hline 16. & Franklin India Prima Fund & G \\
\hline 17. & Franklin India Prima Plus & TP \\
\hline 18. & Franklin India Taxshield & \\
\hline
\end{tabular}


Stock Selection Skills Of Indian Mutual Fund Managers During 2000-2012

\begin{tabular}{|c|c|c|}
\hline 19. & Franklin Infotech Fund & $\mathrm{G}$ \\
\hline 20. & FT India Balanced Fund & $\mathrm{B}$ \\
\hline 21. & HDFC Balanced Fund & $\mathrm{B}$ \\
\hline 22. & HDFC Capital Builder Fund & $\mathrm{G}$ \\
\hline 23. & HDFC Equity Fund & $\mathrm{G}$ \\
\hline 24. & HDFC Growth Fund & $\mathrm{G}$ \\
\hline 25. & HDFC Prudence Fund & $\mathrm{B}$ \\
\hline 26. & HDFC Taxsaver & TP \\
\hline 27. & HDFC Top 200 & $\mathrm{G}$ \\
\hline 28. & ICICI Prudential Balanced & $\mathrm{B}$ \\
\hline 29. & ICICI Prudential FMCG & $\mathrm{G}$ \\
\hline 30. & ICICI Prudential Taxplan & TP \\
\hline 31. & ICICI Prudential Top 100 Fund & $\mathrm{G}$ \\
\hline 32. & ICICI Prudential Top 200 Fund & $\mathrm{G}$ \\
\hline 33. & ICICI Prudential Technology Fund & $\mathrm{G}$ \\
\hline 34. & ING Balanced Fund & $\mathrm{B}$ \\
\hline 35. & ING Core Equity Fund & $\mathrm{G}$ \\
\hline 36. & JM Balanced & $\mathrm{B}$ \\
\hline 37. & JM Basic Fund & $\mathrm{G}$ \\
\hline 38. & JM Equity & $\mathrm{G}$ \\
\hline 39. & Kotak 50 & $\mathrm{G}$ \\
\hline 40. & Kotak Balance & $\mathrm{B}$ \\
\hline 41. & L\&T Opportunities Fund & $\mathrm{G}$ \\
\hline 42. & LIC Nomura Equity Fund & $\mathrm{G}$ \\
\hline 43. & LIC Nomura MF Growth Fund & $\mathrm{G}$ \\
\hline 44. & LIC Nomura Tax Plan & $\mathrm{TP}$ \\
\hline 45. & PRINCIPAL Balanced Fund & $\mathrm{B}$ \\
\hline 46. & PRINCIPAL Index Fund & $\mathrm{G}$ \\
\hline 47. & PRINCIPAL Growth Fund & $\mathrm{G}$ \\
\hline 48. & Reliance Growth & $\mathrm{G}$ \\
\hline 49. & Reliance Vision & $\mathrm{G}$ \\
\hline 50. & Sahara Taxgain & TP \\
\hline 51. & SBI Magnum Balanced Fund & $\mathrm{B}$ \\
\hline 52. & SBI Magnum Equity Fund & $\mathrm{G}$ \\
\hline 53. & SBI Magnum Global Fund 94 & $\mathrm{G}$ \\
\hline 54. & SBI Magnum Multiplier Plus 93 & $\mathrm{G}$ \\
\hline 55. & SBI Magnum Sector Funds Umbrella - Contra & $\mathrm{G}$ \\
\hline 56. & SBI Magnum Sector Funds Umbrella - Pharma & $\mathrm{G}$ \\
\hline 57. & 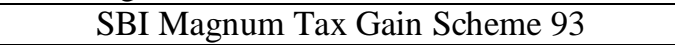 & TP \\
\hline 58. & Sundaram Balanced Fund & $\mathrm{B}$ \\
\hline 59. & Sundaram Growth Fund & $\mathrm{G}$ \\
\hline 60. & Sundaram Taxsaver & TP \\
\hline 61. & Tata Balanced Fund & $\mathrm{B}$ \\
\hline 62. & Tata Ethical Fund & $\mathrm{G}$ \\
\hline 63. & Tata Life Sciences and Technology Fund & $\mathrm{G}$ \\
\hline 64. & $\begin{array}{l}\text { Tata Pure Equity Fund } \\
\end{array}$ & $\mathrm{G}$ \\
\hline 65. & Tata Tax Saving Fund & TP \\
\hline 66. & Taurus Bonanza Fund & $\mathrm{G}$ \\
\hline 67. & Taurus Discovery Fund & $\mathrm{G}$ \\
\hline 68. & Taurus Starshare Fund & $\mathrm{G}$ \\
\hline 69. & Taurus Taxshield & $\mathrm{TP}$ \\
\hline 70. & Templeton India Growth Fund & $\mathrm{G}$ \\
\hline 71. & UTI Balanced Fund & B \\
\hline 72. & UTI Energy Fund & $\mathrm{G}$ \\
\hline 73. & UTI Equity Fund & $\mathrm{G}$ \\
\hline 74. & UTI Equity Tax Savings Plan & $\mathrm{TP}$ \\
\hline
\end{tabular}


Stock Selection Skills Of Indian Mutual Fund Managers During 2000-2012

\begin{tabular}{|c|c|c|}
\hline 75. & UTI Masterplus Unit Scheme 91 & $\mathrm{G}$ \\
\hline 76. & UTI MNC Fund & $\mathrm{G}$ \\
\hline 77. & UTI Pharma and Healthcare Fund & $\mathrm{G}$ \\
\hline 78. & UTI Nifty Fund & $\mathrm{G}$ \\
\hline 79. & UTI Top 100 Fund & $\mathrm{G}$ \\
\hline 80. & UTI Services Industries Fund & $\mathrm{G}$ \\
\hline
\end{tabular}

G-Growth, B-Balanced,TP- Tax Planning

Appendix II- Results of Jensen Models ( Unconditional\&Conditional)

\begin{tabular}{|c|c|c|c|c|c|c|}
\hline Sl. No. & $\boldsymbol{\alpha}$ & $\operatorname{ta}$ & Adj. $R^{2}$ & $\begin{array}{c}\alpha \\
(\mathbf{c})\end{array}$ & $\begin{array}{l}\text { t } \alpha \\
(\mathbf{c})\end{array}$ & Adj. $\mathbf{R}^{2}$ \\
\hline 1 & -0.007022 & -1.276925 & 0.678007 & -0.006611 & -1.140016 & 0.669985 \\
\hline 2 & 0.005797 & 1.793511 & 0.811548 & 0.004447 & 1.325182 & 0.811769 \\
\hline 3 & -0.001160 & -0.326212 & 0.866917 & -0.001716 & -0.472214 & 0.869741 \\
\hline 4 & 0.006710 & 1.399546 & 0.673791 & 0.005630 & 1.161457 & 0.686071 \\
\hline 5 & 0.005184 & 1.385608 & 0.862920 & 0.004535 & 1.173527 & 0.862158 \\
\hline 6 & -0.002475 & -0.400173 & 0.670179 & -0.002653 & -0.412486 & 0.665323 \\
\hline 7 & 0.008481 & $2.183060 *$ & 0.732186 & 0.007971 & 1.967353 & 0.726592 \\
\hline 8 & -0.002085 & -0.297152 & 0.603787 & -0.002380 & -0.324475 & 0.593486 \\
\hline 9 & 0.006735 & $2.365181 *$ & 0.820947 & 0.007424 & $2.530926^{*}$ & 0.821554 \\
\hline 10 & 0.006715 & $2.853033^{*}$ & 0.864726 & 0.007144 & $2.923157 *$ & 0.863049 \\
\hline 11 & 0.007958 & $2.357489 *$ & 0.866397 & 0.007755 & $2.211510^{*}$ & 0.864595 \\
\hline 12 & 0.001106 & 0.174220 & 0.667074 & 0.000720 & 0.108540 & 0.658955 \\
\hline 13 & 0.000679 & 0.174542 & 0.824590 & 0.007785 & $2.736576^{*}$ & 0.900908 \\
\hline 14 & 0.008432 & $3.082347 *$ & 0.902455 & 0.007785 & $2.736576^{*}$ & 0.900908 \\
\hline 15 & 0.000642 & 0.101161 & 0.763475 & 0.001148 & 0.259807 & 0.825947 \\
\hline 16 & 0.012192 & 1.983444 & 0.678030 & 0.011634 & 1.828923 & 0.674993 \\
\hline 17 & 0.009317 & $3.339883^{*}$ & 0.887845 & 0.010047 & 3.469884* & 0.886507 \\
\hline 18 & 0.006837 & $2.239933^{*}$ & 0.879529 & 0.007089 & $2.222101 *$ & 0.876411 \\
\hline 19 & -0.000155 & -0.019685 & 0.514368 & -0.001464 & -0.178280 & 0.506265 \\
\hline 20 & 0.009039 & $3.402675^{*}$ & 0.846294 & 0.008468 & $3.114750 *$ & 0.846197 \\
\hline 21 & 0.006498 & $2.701403 *$ & 0.859774 & 0.004600 & 1.967967 & 0.878249 \\
\hline 22 & 0.008229 & 1.906321 & 0.776974 & 0.008048 & 1.823354 & 0.781364 \\
\hline 23 & -0.001795 & $-12.81295^{*}$ & -0.007450 & -0.001741 & $-19.94515^{*}$ & 0.632860 \\
\hline 24 & 0.008162 & $2.470391 *$ & 0.863265 & 0.006126 & 1.859724 & 0.875041 \\
\hline 25 & 0.013721 & $2.837630 *$ & 0.549793 & 0.009587 & $2.046677^{*}$ & 0.607351 \\
\hline 26 & 0.011368 & $3.296176 *$ & 0.852076 & 0.010436 & $2.945028^{*}$ & 0.853444 \\
\hline 27 & 0.011183 & $3.626229 *$ & 0.886870 & 0.009937 & $3.159065^{*}$ & 0.889559 \\
\hline 28 & 0.005454 & $2.250178^{*}$ & 0.847457 & 0.006101 & $2.464377 *$ & 0.850685 \\
\hline 29 & 0.012149 & $2.248581 *$ & 0.468427 & 0.011571 & $2.092197 *$ & 0.477372 \\
\hline 30 & 0.010383 & $2.128210^{*}$ & 0.768259 & 0.008113 & 1.630413 & 0.773910 \\
\hline 31 & 0.005442 & 1.962420 & 0.889304 & 0.005728 & $2.037023^{*}$ & 0.893202 \\
\hline 32 & 0.006617 & 1.971864 & 0.861908 & 0.006697 & 1.919114 & 0.859685 \\
\hline 33 & 0.001258 & 0.174706 & 0.592628 & -0.001833 & -0.248259 & 0.598260 \\
\hline 34 & -0.000832 & -0.250594 & 0.787065 & -0.000561 & -0.161880 & 0.782089 \\
\hline 35 & -0.003108 & -0.526147 & 0.718409 & -0.001991 & -0.326688 & 0.718656 \\
\hline 36 & -0.003382 & -0.487845 & 0.366964 & -0.001034 & -0.145087 & 0.368988 \\
\hline 37 & -0.015677 & -1.664514 & 0.600934 & -0.015507 & -1.632956 & 0.617054 \\
\hline 38 & -0.002711 & -0.718352 & 0.862416 & -0.001875 & -0.481983 & 0.862004 \\
\hline 39 & 0.003987 & 1.060093 & 0.818674 & 0.005216 & 1.355221 & 0.821795 \\
\hline 40 & -0.001563 & -0.421976 & 0.672025 & -0.000795 & -0.206004 & 0.666294 \\
\hline 41 & -0.003757 & -0.806997 & 0.820888 & -0.002029 & -0.433586 & 0.831523 \\
\hline 42 & -0.002228 & -0.622392 & 0.871708 & -0.000473 & -0.128413 & 0.872438 \\
\hline 43 & -0.001739 & -0.388516 & 0.795971 & -0.003218 & -0.700916 & 0.798521 \\
\hline 44 & -0.003041 & -0.663166 & 0.753481 & -0.002844 & -0.593136 & 0.747027 \\
\hline
\end{tabular}


Stock Selection Skills Of Indian Mutual Fund Managers During 2000-2012

\begin{tabular}{|c|c|c|c|c|c|c|}
\hline 45 & 0.001226 & 0.477431 & 0.882576 & 0.001019 & 0.382150 & 0.880558 \\
\hline 46 & -0.000505 & -0.228799 & 0.937096 & $-9.09 \mathrm{E}-05$ & -0.040040 & 0.937464 \\
\hline 47 & 0.001331 & 0.434495 & 0.885030 & 0.001888 & 0.590695 & 0.882377 \\
\hline 48 & 0.013460 & $2.892479 *$ & 0.791487 & 0.012806 & $2.670038^{*}$ & 0.792136 \\
\hline 49 & 0.012337 & $2.845518^{*}$ & 0.789657 & 0.012440 & $2.748897^{*}$ & 0.784944 \\
\hline 50 & -0.007393 & -0.755407 & 0.478662 & -0.007266 & -0.711855 & 0.464791 \\
\hline 51 & 0.000441 & 0.127101 & 0.802933 & 0.000887 & 0.245039 & 0.798966 \\
\hline 52 & -0.000914 & -0.195191 & 0.760383 & -0.000417 & -0.086465 & 0.761110 \\
\hline 53 & 0.003565 & 0.624672 & 0.733877 & 0.002884 & 0.493607 & 0.738125 \\
\hline 54 & 0.001367 & 0.280105 & 0.780323 & 0.000551 & 0.108732 & 0.777448 \\
\hline 55 & 0.010930 & 0.838219 & -0.009002 & 0.007972 & 0.586991 & -0.027527 \\
\hline 56 & 0.006222 & 1.086319 & 0.563433 & 0.004605 & 0.778320 & 0.569109 \\
\hline 57 & -0.002209 & -0.328610 & 0.629066 & -0.001230 & -0.175449 & 0.621426 \\
\hline 58 & 0.004389 & 1.876206 & 0.880264 & 0.004935 & $2.106759 *$ & 0.886512 \\
\hline 59 & 0.004599 & 1.378953 & 0.881800 & 0.006393 & 1.883302 & 0.885361 \\
\hline 60 & 0.002629 & 0.490610 & 0.721135 & 0.003237 & 0.580455 & 0.716422 \\
\hline 61 & 0.006310 & $2.363084 *$ & 0.835468 & 0.006615 & $2.361155^{*}$ & 0.831775 \\
\hline 62 & 0.004343 & 0.938942 & 0.790476 & 0.004205 & 0.874124 & 0.787169 \\
\hline 63 & 0.005544 & 1.166946 & 0.700511 & 0.001698 & 0.361555 & 0.726915 \\
\hline 64 & 0.006423 & 1.994339 & 0.855571 & 0.005157 & 1.549948 & 0.856535 \\
\hline 65 & -0.001284 & -0.284599 & 0.758212 & -0.002981 & -0.634627 & 0.756187 \\
\hline 66 & 0.004254 & 0.838402 & 0.767073 & 0.003616 & 0.691178 & 0.764217 \\
\hline 67 & -0.005391 & -0.814686 & 0.704197 & -0.005880 & -0.890817 & 0.722061 \\
\hline 68 & 0.004062 & 0.700008 & 0.747459 & 0.003864 & 0.636747 & 0.753343 \\
\hline 69 & 0.001780 & 0.220901 & 0.544559 & 0.003744 & 0.448135 & 0.537670 \\
\hline 70 & 0.007950 & $2.500579 *$ & 0.876641 & 0.007905 & $2.392495^{*}$ & 0.874922 \\
\hline 71 & 0.003534 & 1.460325 & 0.863850 & 0.004080 & 1.616507 & 0.861448 \\
\hline 72 & -0.006200 & -0.646017 & 0.305784 & -0.011313 & -1.184888 & 0.338304 \\
\hline 73 & 0.003659 & 1.053963 & 0.826861 & 0.003733 & 1.004309 & 0.822736 \\
\hline 74 & 0.001519 & 0.339500 & 0.761072 & 0.003447 & 0.730584 & 0.762753 \\
\hline 75 & 0.000202 & 0.082328 & 0.920256 & 0.000203 & 0.077484 & 0.918808 \\
\hline 76 & 0.007338 & 1.882618 & 0.700051 & 0.007585 & 1.872404 & 0.698300 \\
\hline 77 & 0.006662 & 1.276920 & 0.404729 & 0.007724 & 1.382464 & 0.390323 \\
\hline 78 & 0.000715 & 0.331736 & 0.941012 & 0.001544 & 0.679105 & 0.941438 \\
\hline 79 & 0.000492 & 0.062541 & 0.199590 & 0.004120 & 0.541726 & 0.333072 \\
\hline 80 & -0.001553 & 0.005059 & 0.753212 & -0.001619 & -0.295907 & 0.747449 \\
\hline
\end{tabular}

* Significant at $5 \%$ level, (c) indicates conditional

Sl.No. in Appendix II corresponds to the Sl.No. of the sample schemes given in Appendix I.

\section{References}

[1]. Jensen, M.C. (1968): 'The Performance of Mutual Funds in the Period 1945-1964', Journal of Finance, Vol.23 (2), pp.389-415.

[2]. Fama, Eugene F. (1972): 'Components of Investment Performance', Journal of Finance, Vol.27 (3), pp.551-567.

[3]. Grinblatt, M. and S. Titman (1989): 'Portfolio Performance Evaluation: Old Issues and New Insights', Review of Financial Studies, Vol.2 (3), pp. 393-422.

[4]. Ferson,W.E. and R.W. Schadt (1996): 'Measuring Fund Strategy and Performance in Changing Economic Conditions', The Journal of Finance, Vol. L1(2), pp. 425-461.

[5]. Swaicki, J andF.Ong (2000): 'Evaluating Managed Fund Performance Using Conditional Measures: Australian Evidence', PacificBasin Finance Journal, Vol.18, pp.505-528.

[6]. Jayadev, M. (1998): Investment Policy and Performance of Mutual Funds, Kanishka Publishers, New Delhi.

[7]. Irissapane. Aravazhi D, Murugesan B and Rao, Chandrasekhara K.C.S.(2000): 'Portfolio Selection Skill and Timing Abilities of Fund Managers: An Empirical Evidence on Indian Mutual Funds' Fourth Capital Market Proceedings, UTI Institute of Capital Markets, Mumbai.

[8]. Gupta, O.P. and A. Gupta (2004): 'Performance Evaluation of Selected Indian Mutual Fund Schemes: An Empirical Study', The Icfai Journal of Applied Finance, Vol.10 (12), pp.81-98.

[9]. Anand,S. and V.Murugaiah V. (2006): 'Analysis of Components of Investment Performance: An Empirical Study of Mutual Funds in India.' http:// ssrn.com.

[10] Chander, R. (2005): 'Investment Performance of Manager's Stock Selection Abilities: Empirical Evidence from the Indian Capital Market', Decision, Vol. 32 (1), pp. 65-89.

[11] Sehgal, S. and N. Jhanwar (2008): 'On Stock Selection Skills and Market Timing Abilities of Mutual Fund Managers in India', International Research Journal of Finance and Economics, Vol.15, pp. 307-317. 